\title{
An Improved Variable Step Size MPPT Algorithm Based on INC
}

\author{
Zhi-rong Xu ${ }^{\dagger}$, Ping Yang ${ }^{*}$, Dong-bao Zhou ${ }^{* *}$, Peng Li ${ }^{* * *}$, Jin-yong Lei ${ }^{* * *}$, and Yuan-rui Chen ${ }^{* *}$ \\ $\dagger^{* *}$ School of Electric Power, South China University of Technology, Guangzhou, China \\ *Guangdong Key Laboratory of Clean Energy Technology, South China University of Technology, Guangzhou, \\ China \\ ${ }^{* * *}$ Electric Power Research Institute, China Southern Grid (CSG), Guangzhou, China
}

\begin{abstract}
In order to ensure that photovoltaic (PV) systems work at the maximum power point (MPP) and maximize the economic benefits, maximum power point tracking (MPPT) techniques are normally applied to these systems. One of the most widely applied MPPT methods is the incremental conductance (INC) method. However, the choice of the step size still remains controversial. This paper presents an improved variable step size INC MPPT algorithm that uses four different step sizes. This method has the advantages of INC but with the ability to validly adjust the step size to adapt to changes of the PV's power curve. The presented algorithm also simultaneously achieves increased rapidity and accuracy when compared with the conventional fixed step size INC MPPT algorithm. In addition, the theoretical derivation and specific applications of the proposed algorithm are presented here. This method is validated by simulation and experimental results.
\end{abstract}

Key words: Incremental conductance (INC), Maximum power point tracking (MPPT), Photovoltaic (PV), Variable step size

\section{INTRODUCTION}

The environmentally friendly and efficient utilization of nature's resource has been widely studied because of the increasing seriousness of the global energy crisis and environment pollution. The photovoltaic (PV) system, as a newly arisen approach to energy utilization, possesses the following advantages: it is a renewable, pollution-free, abundant resource. However, a PV array's output power changes with the weather conditions (temperature and solar irradiation). Therefore, a maximum power point tracking (MPPT) technique is usually implemented to adjust a PV array to output the maximum power.

In recent years, various techniques have been developed for realizing maximum power point tracking (MPPT) [1]-[13]. These MPPT techniques can be divided into four types:

Manuscript received Aug. 19, 2014; accepted Oct. 31, 2014

Recommended for publication by Associate Editor Woo-Jin Choi.

†Corresponding Author: 407849739@qq.com

Tel: +86-15099963487, South China University of Technology

*Guangdong Key Laboratory of Clean Energy Technology, South China

University of Technology, China

${ }^{* *}$ School of Electric Power, South China University of Tech., China

${ }^{* * *}$ Electric Power Research Institute, China Southern Grid (CSG), China methods based on mathematical models; methods based on output control; methods based on intelligent algorithms; and methods based on disturbance optimization [14].

Fractional open-circuit voltage and short-circuit current [1], [2] methods belong to the first type of method. They provide a simple and effective approach to make the PV system work at the maximum power point (MPP). However, the PV array must be periodically disconnected or short circuited in order to get the open-circuit voltage or short-circuit current as a reference. Therefore, this kind of method increases the power loss and the measured operating points are not the actual maximum power points.

The second type of method includes the output parameters feedback control [3], the DC bus voltage step-down control [4] and the limit cycle control method [5]. The output parameters feedback control method only measures one of the load current and voltage to achieve the maximum power point tracking, and can be simply implemented. However, it is not a real MPPT method. Measurement of the PV array's output parameters is not needed for DC bus voltage stepdown control or limit cycle control methods. However, the dynamic performance and steady state oscillations of the MPPT method rely a lot on the design of the circuit 
parameters, and this is a very complicated process.

As for the third type of method, the fuzzy logic control [6], sliding-mode control [7] and neural-network control [8] methods are commonly applied due to their ability to handle non-linearity. Among these methods, the MPPT fuzzy logic controllers have a satisfactory performance under varying environmental conditions. However their effectiveness depends greatly on the experience of the engineer in determining the division of the fuzzy field and the rule base table. The neural-network algorithm has to be specially trained for each kind of PV array to create the control rules, which limits its versatility. Sliding-mode control can improve the dynamic performance greatly, but it is too complicated for practical use.

The fourth type of method is based on the disturbance optimization, and includes "hill climbing" [9], "perturb and observe" (P\&O) [10] and incremental conductance (INC) [11]-[17] algorithms. "Hill climbing" and P\&O methods are widely applied in PV systems because of their simple realization. The perturbations of the hill climbing and $\mathrm{P} \& \mathrm{O}$ algorithms are the power converter's duty ratio and the PV array's voltage, respectively. Nevertheless, contradictions appear in choosing the perturbation parameter (duty cycle and reference voltage) in both methods. A larger parameter helps to realize faster dynamics, but leads to steady state oscillations that result in a low efficiency. On the other hand, a smaller parameter reduces the response speed under quickly changing conditions. A common characteristic of the INC MPPT methods is that the slope of the PV array power versus the voltage curve changes to zero at the MPP. These methods usually adopt a fixed iteration step size to satisfy the demands of the response speed and the oscillation of the steady state of the MPPT. Hence, it is necessary to design a satisfactory step size to achieve a tradeoff between the steady state oscillations and dynamics [17]. This dilemma can be settled with the variable step size MPPT method. With a variable step size method, a fast dynamic response and stable output can be obtained simultaneously. However, a proportionality factor is always introduced to ensure the convergence of the MPPT algorithm, and once the proportionality factor is chosen, it cannot be changed in the tracking progress. Therefore, the choice of a constant value is very important to achieve a good dynamic and stable state performance. A poor choice of the constant value results in severe steady state oscillations or a very slow dynamic response speed, which increases the power loss of the PV system [13].

Recently, some methods have been presented to solve the above problem. [18] proposes a method to change the scaling factor. The scaling factor is larger at the beginning than during the stable time. At the same time, when the conditions change, its response is slow with a small scaling factor. [19] presents a criterion to make the step size smaller at the MPP. However, to fulfill the algorithm, the voltage value of the

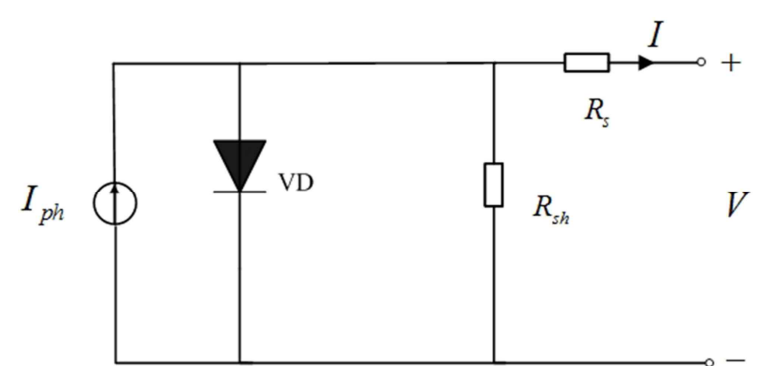

Fig. 1. Equivalent circuit of a PV module.

MPP must be calculated, which results in heavy computational loads. [20] presents a method to remove the $\Delta \mathrm{V}$ for the criterion. When compared to the traditional INC method, this makes the tracking process faster and decreases the transient power loss. However, it is difficult to balance the scaling factors between the start-up process and the steady state.

To solve these problems, an improved variable step size INC MPPT method is presented in this paper. This method has the advantages of INC but with the ability to validly adjust the step size to adapt to changes in the PV's power curve. Furthermore, the relationship between the two fixed step sizes that operate on the two sides of the MPP is provided to make the choice of a step size much easier. The proposed method does not require the constant value mentioned previously and only uses a simple algorithm to ameliorate simultaneously the steady state performance and the dynamic performance.

The structure of paper is as follow: section II presents a single-diode model for the PV cell, as well as an illustration of both the conventional variable step size MPPT algorithm and the proposed algorithm. To verify the validity of the proposed method, some simulation and experiment results are shown in section III and section IV, respectively. The main results are summarized in the conclusion.

\section{Photovoltaic CELl Model AND MPPT}

\section{A. PV Cell Model}

Generally, a PV cell is modeled as a current source shunted with a diode. Its equivalent circuit [16] is shown in Fig. 1 and the $I-V$ characteristic of a $\mathrm{PV}$ cell is given by the following equation [9]:

$$
I=I_{p h}-I_{s}\left\{\exp \left[\frac{q}{A k T}\left(V+I R_{s}\right)\right]-1\right\}-\frac{V+I R_{s}}{R_{s h}}
$$

where:

$$
\begin{gathered}
I_{s}=I_{\text {sref }}\left(\frac{T}{T_{\text {ref }}}\right)^{3} \exp \left[\frac{q E_{g}}{A k}\left(\frac{1}{T_{\text {ref }}}-\frac{1}{T}\right)\right] \\
I_{p h}=\left[I_{\text {scref }}+K_{I}(T-25)\right] \lambda / 100
\end{gathered}
$$

$I \quad$ is the output current of the PV module;

$V \quad$ is the output voltage;

$I_{p h} \quad$ is the generated current under a given isolation; 
$I_{s} \quad$ is the cell reverse saturation current that depends mainly on the temperature;

$q \quad$ is the charge of an electron;

$k \quad$ is the Boltzmann's constant;

$A$ is the ideality factor for a $\mathrm{P}-\mathrm{N}$ junction;

$T \quad$ is the cell temperature $\left({ }^{\circ} \mathrm{C}\right)$;

$R_{s} \quad$ is the intrinsic series resistance of the PV module;

$R_{s h} \quad$ is the shunt resistance;

$I_{\text {sref }} \quad$ is the cell reverse saturation current at $T_{\text {ref }}$;

$E_{g} \quad$ is the band gap for silicon;

$I_{\text {scref }}$ is the short circuit current at $25^{\circ} \mathrm{C}$ and $1000 \mathrm{~W} / \mathrm{m}^{2}$;

$K_{I} \quad$ is the short circuit current temperature coefficient;

$\lambda \quad$ is the solar irradiation in $W / \mathrm{m}^{2}$.

The output power of the PV module is given by $P=V^{*} I$.

\section{B. Variable Step Size INC MPPT Algorithm}

Generally, the INC MPPT method adopts a fixed step size. A larger parameter helps to realize faster dynamics, but leads to steady state oscillations and low efficiency. On the other hand, a smaller parameter reduces the response speed in quickly changing conditions. Hence, it is necessary to design a satisfactory step size for a tradeoff between steady state oscillations and dynamics [17]. This dilemma can be settled with the variable step size MPPT method. The fixed step size is replaced by the derivative of the power to voltage $(\mathrm{dP} / \mathrm{dV})$ to achieve fast dynamic tracking and small steady state oscillation, because the value of the derivative will become zero when the system arrives at the MPP. A proportionality factor $\mathrm{N}$ is introduced to ensure the convergence of the MPPT algorithm in [21], as bellow:

$$
D(k)=D(k-1) \pm N *\left|\frac{d P}{d V}\right|=D(k-1) \pm N *\left|\frac{P(k)-P(k-1)}{V(k)-V(k-1)}\right|
$$

In [22], the slope of the P-D curve is used to realize the variable step size.

$$
D(k)=D(k-1) \pm N\left|\frac{\Delta P}{\Delta D}\right|
$$

$\Delta \mathrm{D}$ is the step variety of the duty cycle in a sampling period. According to (4) and (5), the choice of proportionality factor $\mathrm{N}$ greatly impacts the efficiency of the PV system. Therefore, the constant value $N$ must be chosen carefully. A simple method is proposed in [12] to ascertain the proportionality factor when the system approaches the steady state. The following inequality must be obeyed to assure the convergence of the MPPT methods:

$$
N *\left|\frac{d P}{d V}\right|_{\text {fixed, step }=\Delta D_{\max }}<\Delta D_{\max }
$$

Where $\Delta D_{\max }$ is the largest step size for a fixed step size MPPT method and the upper limitation for the variable step size INC MPPT method. Hence, the proportionality factor can be determined as:

$$
N<\Delta D_{\max } /\left|\frac{d P}{d V}\right|_{\text {fixed }, \text { step }=\Delta D_{\max }}
$$

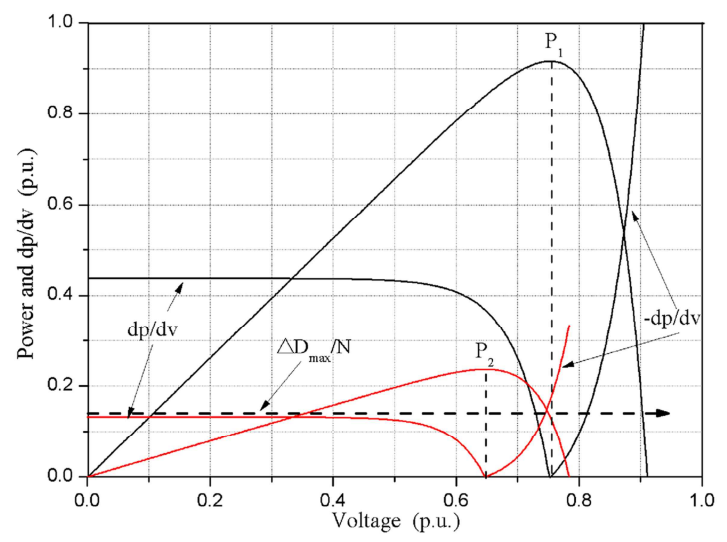

Fig. 2. Curves of power and its slope.

The variable step size keeps the fixed step size $\Delta D_{\max }$ once equation (7) cannot be satisfied. It is simple to ascertain the proportionality factor by equation (7).

However, [13] and [24] note that the proportionality factor $\mathrm{N}$ cannot be changed in the tracking progress once it is chosen. In addition, when the irradiation or temperature conditions change greatly, this simple method cannot provide an effective fixed proportionality factor for the MPPT. According to Fig. 2, power $P_{1}$ is much larger than power $P_{2}$ $\left(P_{1}>>P_{2}\right)$, and $N$ is obtained from (7). The proportionality factor $N$ almost cannot make the variable step size MPPT algorithm work in the area of the variable step size for the $P_{l}$ curve. This causes severe steady state oscillations and increases the power loss. On the other hand, the same proportionality factor $N$ always makes the PV system operate within the variable step-size area for the $P_{2}$ curve. This decreases the dynamic response speed and the overall output power.

In [13], the step size modes of the INR MPPT are switched by a threshold function. Its equation is as follows:

$$
C=P^{*}|d P / d I|
$$

The product $(C)$ curve has two extreme points at the two sides of the MPP. When the operating point is between the two extreme points, the MPPT algorithm works in the variable step-size mode with a variable proportionality factor of $|d P / d \mathrm{I}| / \sqrt{1+|d P / d \mathrm{I}|^{2}}$. Otherwise, it works in the fixed step size mode. Although this method can ameliorate the steady-state performance and dynamic response speed, it generates fairly heavy computational loads due to too many derivatives, such as the computational process of the two extreme points and the proportionality factor. There still exists a strong non-linearity in the expression of the proportionality factor and the threshold function $\mathrm{C}$, because the $\mathrm{P} / \mathrm{I}$ derivative term shows a higher non-linearity than the $\mathrm{P} / \mathrm{V}$ derivative term [17]. In addition, [25] points out that the occurrence of irradiance drops might lead to a failure of the configurations based on the direct regulation of the PV current. 


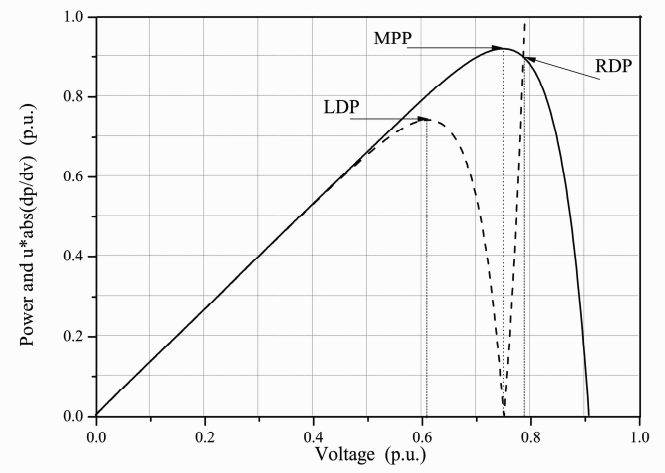

Fig. 3. PV power, the product of voltage and the slope of power versus voltage

\section{Improved MPPT Algorithm}

An improved variable step size MPPT algorithm is presented to ameliorate the steady-state performance and the dynamic response speed. The improved algorithm proposes a special threshold function $(M)$, which is a product of the output voltage $(V)$ and the absolute value of the PV array power derivative $(|d P / d V|)$.

$$
M=V *|d P / d V|
$$

Fig. 3 shows the curves of threshold function $(M)$ and output power $(P)$ versus the voltage $(V)$.

The operational mode of the INC MPPT is shifted by the left dividing point (LDP) and the right dividing point (RDP). As shown in Fig.3, the product curve has a left dividing point corresponding to the voltage value $\left(\mathrm{V}_{1}\right)$ at the left side of the MPP and a right dividing point corresponding to the voltage value $\left(V_{2}\right)$ at the right side of the MPP. When the PV array operational point is between the LDP and the RDP, the INC MPPT runs in the variable step size mode. Otherwise, it works in the fixed step size mode. This process can be expressed as:

$$
\begin{cases}\Delta M / \Delta V \geq 0, & \text { fixed step size mode } \\
& \text { (left of the LDP); } \\
\Delta M / \Delta V<0, & \text { variable step size mode } \\
& \text { (between the LDP and the MPP); } \\
P-M \geq 0, & \begin{array}{l}
\text { variable step size mode } \\
\text { (between the MPP and the RDP) } \\
\text { fixed step size mode } \\
\text { (right of the RDP) }
\end{array}\end{cases}
$$

Where $\Delta \mathrm{M} / \Delta \mathrm{V}$ is the increment of the threshold function. Two maximum step sizes $d_{l}$ and $d_{2}$ are initially determined for the fixed step size mode. $d_{1}$ works in the left side of the LDP while $d_{2}$ works in the right side of the RDP. The relationship between $d_{1}$ and $d_{2}$ can be expressed as:

$$
\frac{d_{1}}{d_{2}}=\frac{V_{m}}{V_{o c}-V_{m}}
$$

Where $V_{m}$ and $V_{o c}$ are the PV array voltages corresponding to the MPP and the open circuit voltage, respectively. When the irradiation or temperature condition changes, the corrections of $V_{m}$ and $V_{o c}$ can be obtained as [23]:

$$
\begin{aligned}
& V_{o c}=V_{o c r e f} \cdot \operatorname{In}[e+b(S-1000)] \cdot[1-c(T-25)] \\
& V_{m}=V_{\text {mref }} \cdot \operatorname{In}[e+b(S-1000)] \cdot[1-c(T-25)]
\end{aligned}
$$

Where $V_{\text {mref }}$ and $V_{\text {ocref }}$ are the $\mathrm{PV}$ array voltages corresponding to the MPP and the open circuit voltage, respectively, under the standard testing conditions (sunlight intensity $S=1000 \mathrm{~W} / \mathrm{m}^{2}$, PV cell temperature $T=25^{\circ} \mathrm{C}$ ), where $T$ is the temperature of the PV array, $S$ is the irradiation, $b$ and $c$ are the irradiation and temperature coefficients, and $e$ is the nature base.

From the expressions (11)-(13), it is easy to deduce that:

$$
\frac{d_{1}}{d_{2}}=\frac{V_{\text {mref }}}{V_{\text {ocref }}-V_{\text {mref }}}
$$

The ratio of $d_{1}$ versus $d_{2}$ is a constant once the values of $V_{\text {mref }}$ and $V_{\text {ocref }}$ are determined, and both of them can be obtained from the PV array manufacturer. Therefore, expression (14) reflects the relationship between $d_{1}$ and $d_{2}$ regardless of changes in the temperature and irradiation.

A control flowchart of the improved MPPT algorithm is represented in Fig.4. It illustrates the details of the decision process. As shown in Fig.4, the proposed MPPT method is based on the conventional INC MPPT method with step size variation.

In [9], the control signal of the converter duty cycle is directly determined by the PV output power [9]. Note that $V(k), I(k)$ and $M(k)$ are the PV array output voltage, current and the proposed threshold function $(M)$ at time $\mathrm{k}$, respectively. In addition, $D(k)$ and $\Delta D(k)$ are the converter duty cycle and its change (step size) at time $\mathrm{k}$.

To ensure the convergence of the MPPT method, [12] adopts a scaling factor. However, it uses a constant value and produces a dead band. [13] introduces a proportionality factor of $|d P / d \mathrm{I}| / \sqrt{1+|d P / d \mathrm{I}|^{2}}$ to determine the variable step size. However, it results in a heavy computational load. To solve those problems, this paper presents an improved and simple MPPT method for its convergence and effectiveness. When the PV array output voltage is between $V_{l}$ and $V_{2}$, the value of the function $M / P$ meets the following inequality:

$$
0 \leq M / P \leq 1
$$

When the MPP is reached, the value of $M / P$ is equal to zero. The inequality can also be deduced as follows:

(1) At the left side of the MPP, $M=V *|d P / d V| \geq 0$, the proportionality factor $N$ is defined as:

$$
N=\frac{M}{P}=\frac{V^{*}|d P / d V|}{P}=\frac{d P / d V}{I}=1+\frac{V}{I} * \frac{d I}{d V}
$$

$d I / d V<0$. As a result, $0<N<1$.

(2) At the right side of the MPP, as previously stated, there exists an equivalent point at $V_{2}$, which means that the value of the threshold function $\mathrm{M}$ is equal to the output power $P$. When the operating point is between the MPP and the RDP, 


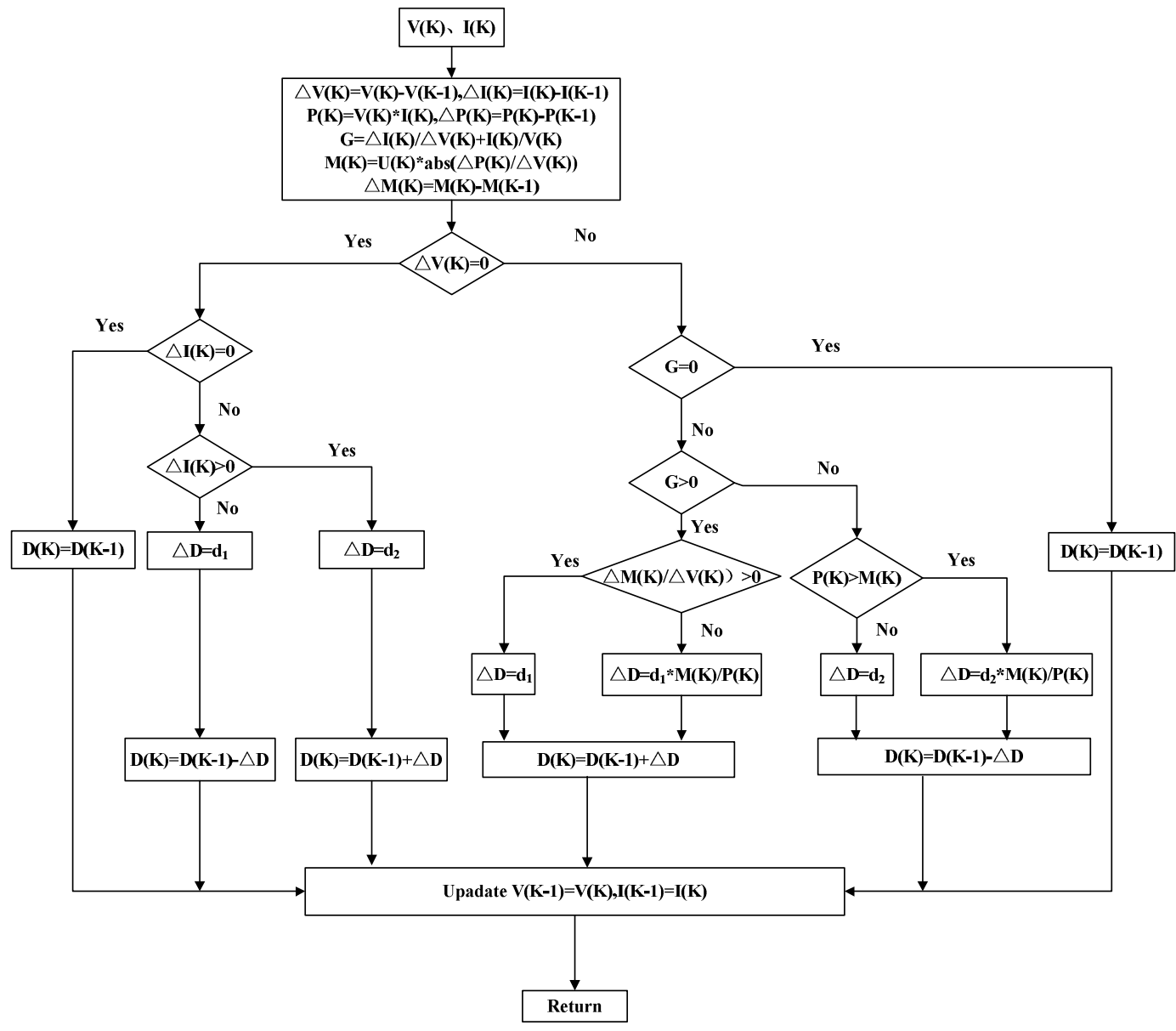

Fig. 4. Flowchart of the improved MPPT algorithm.

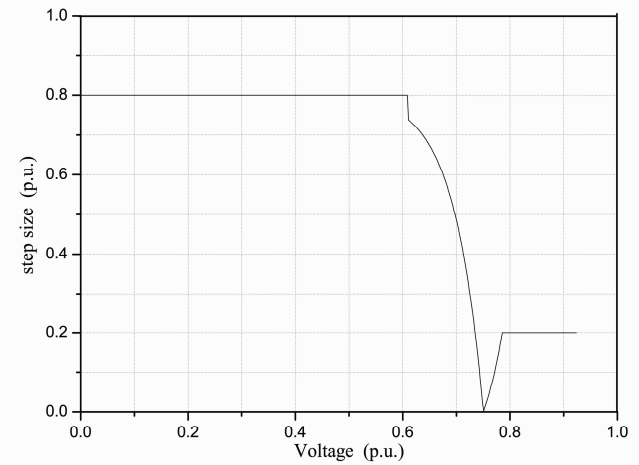

Fig. 5. The step size of the improved MPPT algorithm.

$M$ is equal or less than $P$. Therefore, the value range of $N$ can be expressed as $0<N \leq 1$.

(3) At the MPP, the value of the threshold function $M$ is equal to zero, hence $N=0$.

With $d_{1}$ and $d_{2}$ chosen as fixed step sizes (they are also the upper limitations for the MPPT algorithm), the variable step size can be determined by the following equation:

$$
S(k)=\frac{M(k)}{P(k)} * d \quad k=0,1,2 \ldots
$$

Where $S(k), M(k)$ and $P(k)$ are the variable step size, the value of the threshold function $(M)$, and the PV array output power at time $k$, respectively. The fixed step size $\mathrm{d}$ is defined as:

$$
d= \begin{cases}d_{1} & 0 \leq V \leq V_{m p} \\ d_{2} & V_{m p} \leq V \leq V_{o c}\end{cases}
$$

Fig. 5 shows the step size of the proposed algorithm. For the left side of the LDP and the right side of the RDP, the system works in the fixed step size mode. When the operating point is between the LDP and the RDP, the system works in the variable step size mode. When the operational point closes to the MPP, the step size will decrease to zero.

\section{SIMULATION ANALYSIS}

Fig. 6 shows a simulation model of the PV system, which is developed in Matlab/Simulink for algorithm validation. A silicon PV module is presented for the PV array model in the simulation, and the parameters of the PV module are listed in Table I. To realize the MPPT algorithm and the power interface between the load and the PV array, a boost converter is presented. The parameters of the boost converter are listed in Table II. 
TABLE I

PARAMETERS OF THE PV MOdULE

\begin{tabular}{cc}
\hline Open voltage & $44.2 \mathrm{~V}$ \\
Short current & $5.2 \mathrm{~A}$ \\
Voltage (MPP) & $35.7 \mathrm{~V}$ \\
Current (MPP) & $4.95 \mathrm{~A}$ \\
Rated power & $177 \mathrm{~W}$ \\
\hline
\end{tabular}

TABLE II

PARAMETERS OF THE BOOST CONVERTER

\begin{tabular}{ll}
\hline$L$ & $1 \mathrm{mH}$ \\
$C_{i n}$ & $165 \mathrm{uF}$ \\
$C_{o}$ & $2500 \mathrm{uF}$ \\
Switching frequency & $20 \mathrm{kHz}$ \\
\hline
\end{tabular}

TABLE III

Comparison of the Tracking Performance Results

\begin{tabular}{|c|c|c|c|c|}
\hline \multirow[t]{2}{*}{ Method } & \multirow{2}{*}{ Parameters } & \multirow{2}{*}{$\begin{array}{l}\text { Average Power } \\
\text { at } 1000 \mathrm{~W} / \mathrm{m}^{2}\end{array}$} & \multicolumn{2}{|c|}{ Tracking time with irradiation step change } \\
\hline & & & 1000 to $300 \mathrm{~W} / \mathrm{m}^{2}$ & 300 to $1000 \mathrm{~W} / \mathrm{m}^{2}$ \\
\hline \multirow{2}{*}{$\begin{array}{c}\text { Fixed } \\
\text { step size }\end{array}$} & $\mathrm{d}=0.001$ & $174.95 \mathrm{~W}$ & $57 \mathrm{~ms}$ & $64 \mathrm{~ms}$ \\
\hline & $\mathrm{d}=0.004$ & $173.43 \mathrm{~W}$ & $11.2 \mathrm{~ms}$ & $17 \mathrm{~ms}$ \\
\hline \multirow{2}{*}{$\begin{array}{l}\text { Variable } \\
\text { step size }\end{array}$} & $\begin{array}{l}\mathrm{d}_{1}=0.004 \\
\mathrm{~d}_{2}=0.004\end{array}$ & $175.14 \mathrm{~W}$ & $16.5 \mathrm{~ms}$ & $18 \mathrm{~ms}$ \\
\hline & $\begin{array}{c}\mathrm{d}_{1}=0.0168 \\
\mathrm{~d}_{2}=0.004\end{array}$ & $175.01 \mathrm{~W}$ & $15.7 \mathrm{~ms}$ & $6.7 \mathrm{~ms}$ \\
\hline
\end{tabular}

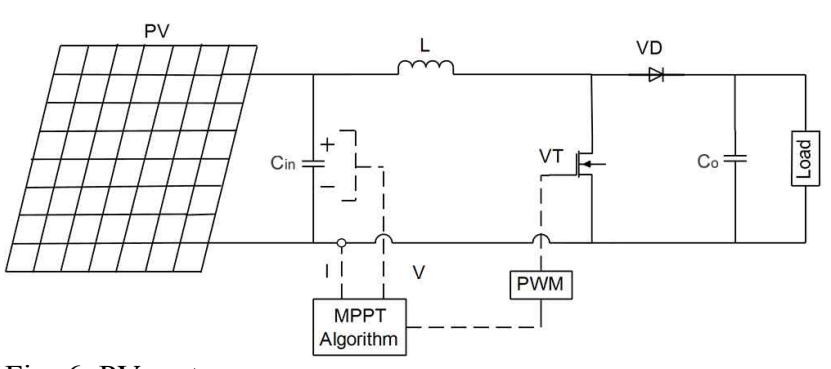

Fig. 6. PV system.

The simulations are conducted under the same conditions to verify the effectiveness and feasibility of the improved method. Fig. 7(a)-(d) exhibit the output performance of the fixed step size INC MPPT under the conditions of stepchanges in the irradiation. The irradiation is suddenly changed from $1000 \mathrm{~W} / \mathrm{m}^{2}$ to $300 \mathrm{~W} / \mathrm{m}^{2}$ at $0.10 \mathrm{~s}$ and it rises up to $1000 \mathrm{~W} / \mathrm{m}^{2}$ at $0.20 \mathrm{~s}$.

For the improved variable step size INC MPPT algorithm, both of the initial fixed step sizes $d_{1}$ and $d_{2}$ are set as 0.004 . The PV output power and duty cycle are shown in Fig. 8(a) and $8(\mathrm{~b})$. In addition, Fig. 8(c) and 8(d) illustrate the PV output power and duty cycle with different initial step sizes $\left(d_{1}=0.0168\right.$ and $\left.d_{2}=0.004\right)$. This also satisfies expression (12).

Comparative results of the different MPPT algorithms are summarized in Table III. Fig.7 (a)-(d) show the simulation results with fixed step sizes of 0.001 and 0.004 . It is obvious that a larger step size contributes to better dynamic performance and a smaller step size decreases the steady state oscillations. Specifically, the tracking times of the MPPT method with a fixed step size of 0.001 are $57 \mathrm{~ms}$ and $64 \mathrm{~ms}$, which can be decreased greatly with a lager step size. However, the lager step size results in a lower efficiency. The PV array average output power with a fixed step size of 0.004 is $173.43 \mathrm{~W}$. This rises up to $174.95 \mathrm{~W}$ with a step size of 0.001. From Fig. 8(a)-(d), it can be seen that the improved variable step size algorithm has settled the dilemma. When the operation point approaches the MPP, the step size becomes very small. Hence, the output powers of the PV array are above $175.01 \mathrm{~W}$ and the oscillations at the steady state are decreased.

In addition, when compared with the dynamic performance of a fixed step size of 0.001 , the improved algorithm has a better performance. In addition, the improved algorithm with different initial step sizes in Fig. 8(c) has a shorter tracking time than the same initial step size algorithm in Fig. 8(a), while the steady-state oscillations illustrate that there is almost no difference between two algorithms. The presented method in this paper can achieve a fast tracking response and a stable output power simultaneously even under enormous irradiation change conditions. Thus, it is more suitable for actual solar-energy power systems in terms of tracking the MPP.

\section{EXPERIMENTAL RESULTS}

Fig. 9 shows the experimental setup. It consists of a Programmable DC Power Supply with a SAS mode (Chroma Solar Array Simulator, 62000H series), an oscilloscope (Agilent Technologies DSO7014B), a DSP controller (TMS320F28035) and a boost circuit connected to the load. The $62000 \mathrm{H}$ series simulator provides a unique feature in that it can simulate the output characteristics and test the MPPT performance evaluation of a solar array via softpanel. When the improved INC method is written in $\mathrm{C}$ language and compiled by an CSS compiler from TI, the program is downloaded into the digital signal processor (TMS320F28035) to realize the MPPT method.

Fig. 10 shows a start-up process comparison between the traditional method and the improved method. The time scale in the waveform is $2 \mathrm{~s} /$ div. Fig. 10(a) shows the start-up process of the traditional method, which takes $2.84 \mathrm{~s}$ to reach the MPP. However, Fig. 10(b) shows the start-up process of the improved method, which takes $2.38 \mathrm{~s}$ to reach the MPP. That is $0.46 \mathrm{~s}$ faster than the traditional method. 


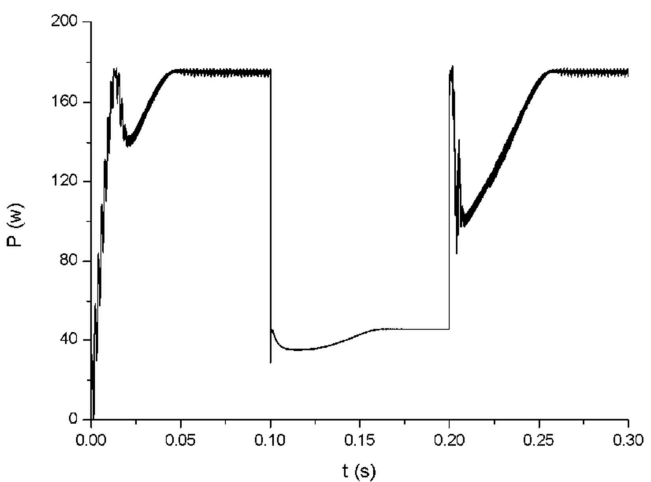

(a)

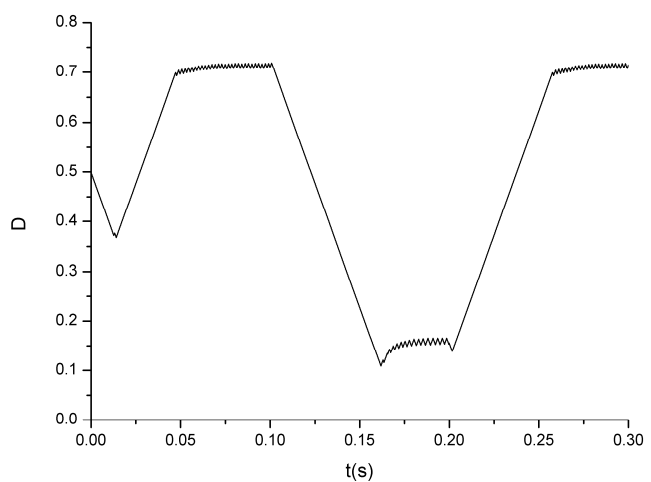

(b)

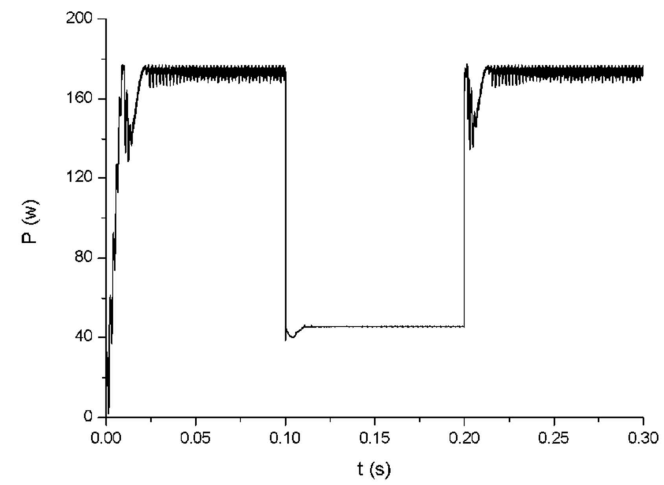

(c)

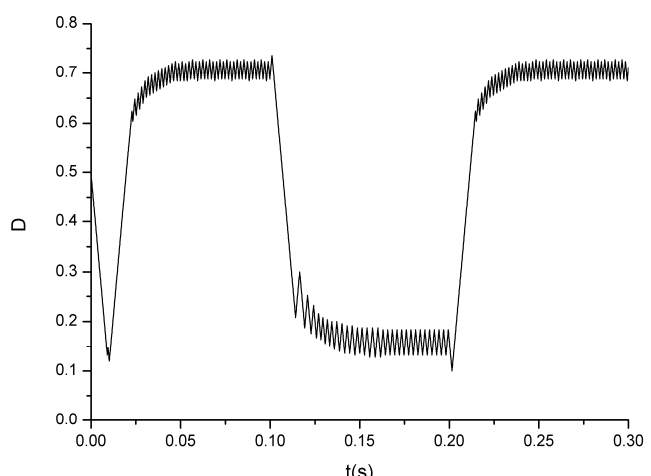

(d)

Fig. 7. Traditional MPPT algorithm. (a) PV array output power with fixed step size of 0.001 . (b) Duty cycle (step size) with fixed step size of 0.001 . (c) PV array output power with fixed step size of 0.004 . (d) Duty cycle (step size) with fixed step size of 0.004 .

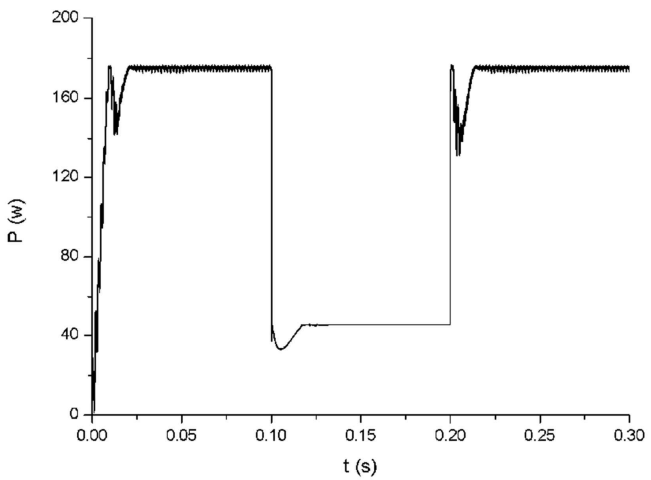

(a)



(b)



(c)

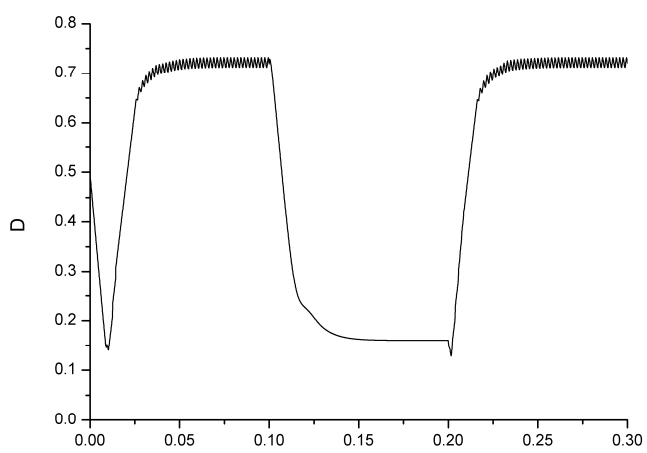

(d)

Fig. 8. Improved MPPT algorithm. (a) PV array output power with $\mathrm{d}_{1}=\mathrm{d}_{2}=0.004$. (b) Duty cycle (step size) with $\mathrm{d}_{1}=\mathrm{d}_{2}=0.004$. (c) PV array output power with $\mathrm{d}_{1}=0.0168, \mathrm{~d}_{2}=0.004$. (d) Duty cycle (step size) with $\mathrm{d}_{1}=0.0168, \mathrm{~d}_{2}=0.004$. 


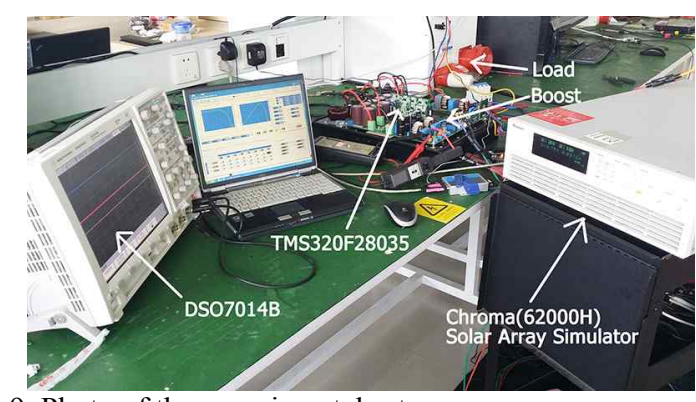

Fig. 9. Photo of the experimental setup.

TABLE IV

PARAMETERS OF THE PV MODULE

\begin{tabular}{ll}
\hline Open voltage & $320.8 \mathrm{~V}$ \\
Short current & $0.901 \mathrm{~A}$ \\
Voltage (MPP) & $250 \mathrm{~V}$ \\
Current (MPP) & $0.8 \mathrm{~A}$ \\
Rated power & $200 \mathrm{~W}$ \\
\hline
\end{tabular}

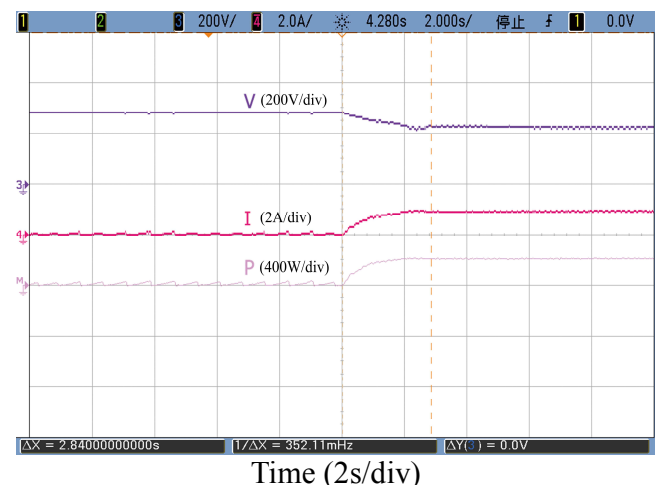

(a)

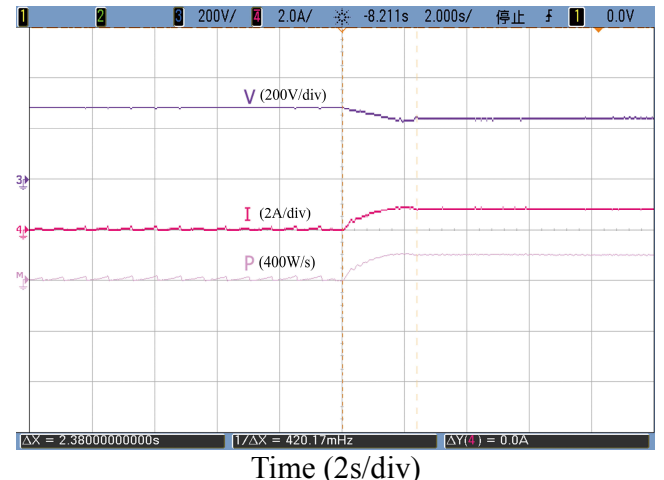

(b)

Fig. 10. The start-up process. (a) The traditional method. (b) The improved method.

The parameters of the PV module are given in Table IV.

In order to stimulate variations in the irradiation, the experiment changes the number of PV cells in parallel by setting the solar array simulator. Fig. 11 shows the rise-up situation of the PV power. The number of PV cells changes from 6 to 15 , meaning that the power changes from $1200 \mathrm{w}$ to 3000 w. Fig. 11(a) describes the situation of a sudden increase in the irradiation using the traditional method. It takes $3.92 \mathrm{~s}$ to reach the MPP. The steady-state power changes from

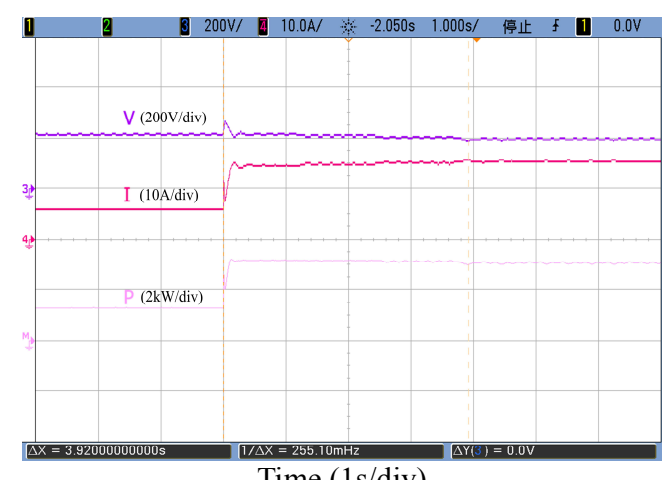

Time (1s/div)

(a)

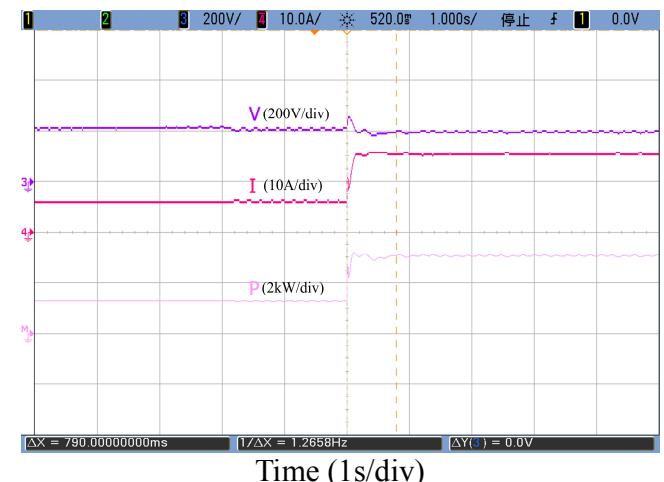

(b)

Fig. 11. The rise-up situation. (a) The traditional method. (b) The improved method.

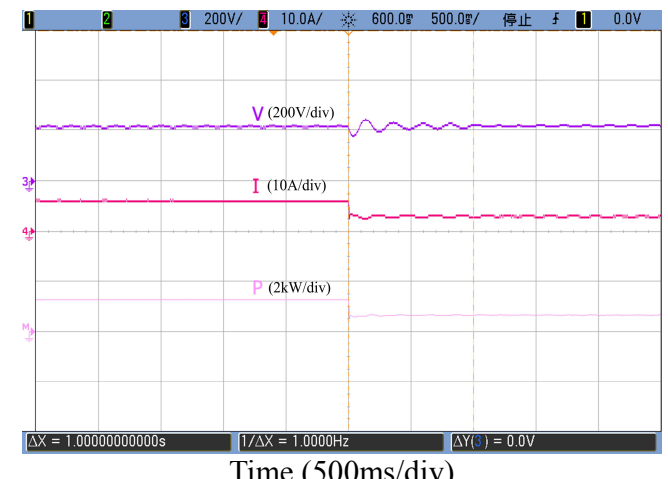

(a)

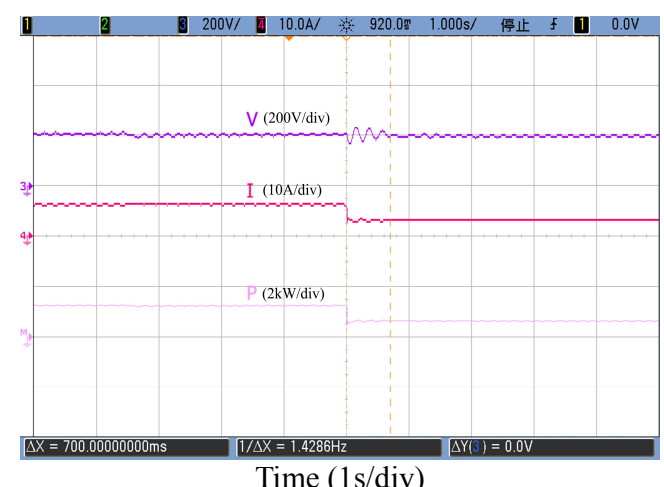

(b)

Fig. 12. The decreasing situation. (a) The traditional method. (b) The improved method. 


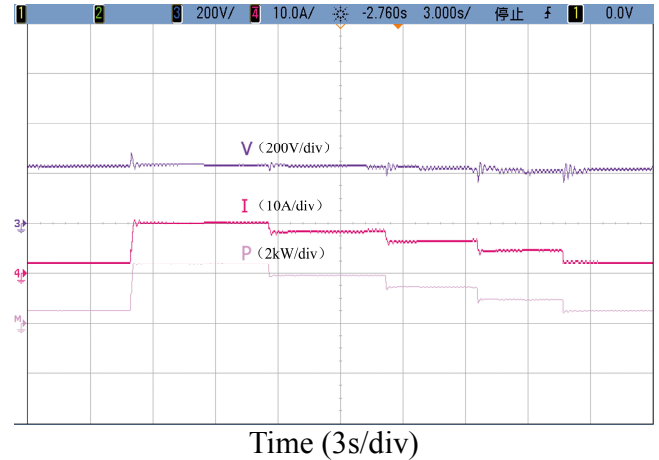

Fig. 13. The response situation.

$1159 \mathrm{w}$ to $2925 \mathrm{w}$, which means that the MPPT efficiency changes from $96.6 \%$ to $97.5 \%$. Fig. 11(b) illustrates the changing situation using the improved method. This takes $0.79 \mathrm{~s}$, which is a lot faster than the traditional method. The steady-state power changes from $1186 \mathrm{w}$ to $2974 \mathrm{w}$, which means the MPPT efficiency changes from $98.8 \%$ to $99.1 \%$.

Fig. 12 shows the decreasing situation of the PV power. The number of PV cells changes from 6 to 2, meaning that the power changes from $1200 \mathrm{w}$ to $600 \mathrm{w}$. Fig. 12 (a) describes the situation of a sudden decrease in the irradiation using the traditional method. It takes $1.00 \mathrm{~s}$ to reach the MPP. The steady-state power changes from $1159 \mathrm{w}$ to $583 \mathrm{w}$, which means that the MPPT efficiency changes from $96.6 \%$ to 97.1\%. Fig. 12(b) exhibits the changing situation using the improved method. It takes $0.70 \mathrm{~s}$, which is $0.3 \mathrm{~s}$ faster than the traditional method. The steady-state power changes from 1186 w to $591 \mathrm{w}$, which means that the MPPT efficiency changes from $98.8 \%$ to $98.5 \%$.

Fig. 13 demonstrates the response situation of the improved method. The power change path is $400 \mathrm{~W}-2400 \mathrm{~W}-$ $2000 \mathrm{~W}-1400 \mathrm{~W}-1000 \mathrm{~W}-400 \mathrm{~W}$. The response times of the five changing moments are $578 \mathrm{~ms}-296 \mathrm{~ms}-500 \mathrm{~ms}-394 \mathrm{~ms}-644 \mathrm{~ms}$, proving the effectivity of the improved method. The experimental results confirm both the good tracking performance and the stable output power.

\section{CONCLUSION}

This paper presents an improved variable step size INC MPPT algorithm, which has the advantages of traditional INC but with the ability to validly adjust the step size to adapt to changes in the PV's power curve. It enables both the dynamic response speed and the steady state oscillation to be satisfactory. The proposed method only uses a simple algorithm with a light computation load to realize the tracking of the MPP. Thus, it can be easily realized with a digital signal processor (DSP). This paper also discusses the design scheme in great detail and presents a quite simple but effective realization rule for the fixed step sizes. The fixed step size algorithm and the improved variable step size algorithm are simulated in Matlab/Simulink under the same conditions. In addition, hardware experiments are conducted with a DSP (TMS320F28035). The effectiveness and feasibility of the improved algorithm are validated by the simulation and experimental results.

\section{ACKNOWLEDGMENT}

The authors would like to thank the support from the National High-tech R\&D Program (863 Program) of China (2014AA052001), and Guangdong Strategic Emerging Industry Core Technology Research Projects (2012A032300001).

\section{REFERENCES}

[1] J. J. Schoeman and J. D. van Wyk, "A simplified maximal power controller for terrestrial photovoltaic panel arrays," PESC'82; 13th Annual Power Electronics Specialists Conference. Vol. 1, 1982.

[2] M. A. S. Masoum, H. Dehbonei, and E. F. Fuchs, "Theoretical and experimental analyses of photovoltaic systems with voltage and current-based maximum powerpoint tracking," IEEE Trans. Energy Convers., Vol. 17, No. 4, pp. 514-522, Dec. 2002.

[3] D. Shmilovitz, "On the control of photovoltaic maximum power point tracker via output parameters," in Proc. Electric Power Applications, Vol. 152, No. 2, pp. 239-248, 2005.

[4] T. Kitano, M. Matsui, and D. Xu, "Power sensor-less MPPT control scheme utilizing power balance at DC linksystem design to ensure stability and response," IEEE Annual Conference of the Industrial Electronics Society, Vol. 2, pp. 1309-1314, 2001.

[5] M. Matsui, T. Kitano, and D. Xu, "A simple maximum photovoltaic power tracking technique utilizing system inherent limit cycle phenomena," IAS Annual Meeting of the Industry Applications Conference, pp. 2041-2047, 2003.

[6] B. N. Alajmi, K.H. Ahmed, and S. J. Finney, "Fuzzylogic-control approach of a modified hill-climbing method for maximum power point in microgrid standalone photovoltaic system," IEEE Trans. Power Electron., Vol. 26, No. 4, pp.1022-1030, Apr. 2011.

[7] S. Kim, M. B. Kim, and M. J. Youn, "New maximum power point tracker using sliding-mode observer for estimation of solar array current in the grid-connected photovoltaic system," IEEE Trans. Ind. Electron., Vol.53, No.4, pp. 1027-1035, Jun. 2006.

[8] A. M. Kassem, "MPPT control design and performance improvements of a PV generator powered DC motorpump system based on artificial neural networks," International Journal of Electrical Power \& Energy Systems, Vol. 43, No. 1, pp. 90-98, Dec. 2012.

[9] E. Koutroulis, K. Kalaitzakis, and N. C. Voulgaris, "Development of a microcontroller-based, photovoltaic maximum power point tracking control system," IEEE Trans. Power Electron., Vol. 16, No. 1, pp. 46-54, Jan. 2001.

[10] C. Hua, J. Lin, and C. Shen, "Implementation of a DSPcontrolled photovoltaic system with peak power tracking," IEEE Trans. Ind. Electron., Vol. 45, No. 1, pp. 99-107, 
Feb. 1998.

[11] K. H. Hussein, I. Muta, T. Hoshino, et al. "Maximum photovoltaic power tracking: an algorithm for rapidly changing atmospheric conditions," IEE Proc. Generation, Transmission and Distribution, Vol. 142, No. 1, pp. 59-64, 1995.

[12] F. Liu, S. Duan, F. Liu, B. Liu, and Y. Kang, "A variable step size INC MPPT method for PV systems," IEEE Trans. Ind. Electron., Vol. 55, No. 7, pp. 2622-2628, Jul. 2008.

[13] Q. Mei, M. W. Shan, L. Y. Liu, and J. M. Guerrero, "A Novel Improved Variable Step-Size IncrementalResistance MPPT Method for PV Systems," IEEE Trans. Ind. Electron., Vol. 58, No. 6, pp. 2427-2434, Jun. 2011.

[14] L. Zhou, J. Wu, Q. H. Li, and K. Guo, "Survey of maximum power point tracking techniques for photovoltaic array," Journal of High Voltage Engineering, Vol. 34 , No. 6, pp. 1145-1154, 2008.

[15] C. Zhang, Z. Zhang, M. Chen, Z. Qian, “An improved variable step-size maximum power point tracking (MPPT) based on extremum seeking control (ESC) in girdconnected photovoltaic micro-converter system," Industrial Electronics (ISIE), 2012 IEEE International Symposium on, pp. 1765-1770, 2012.

[16] I. R. Balasubramanian, S. I. Ganesan, and N. Chilakapati, "Impact of partial shading on the output power of PV systems under partial shading conditions," IEEE Trans. Power Electron., Vol. 7, No. 3, pp. 657-666, Mar. 2014.

[17] A. K. Abdelsalam, A. M. Massoud, S. Ahmed, and P. Enjeti, "High-performance adaptive perturb and observe MPPT technique for photovoltaic-based microgrids," IEEE Trans. Power Electron., Vol. 26, No. 4, pp. 10101021, Apr. 2011.

[18] N. H. Abdul Rahman, A. M. Omar, and E. H .Mat Saat, "A modification of variable step size INC MPPT in PV system," in Proc. IEEE PEOCO, pp. 340-345, 2013

[19] R. Faraji, A. Rouholamini, H. R. Naji, and R. Fadaeinedjad, "FPGA-based real time incremental conductance maximum power point tracking controller for photovoltaic systems," IET Power Electronics, Vol. 7, No. 5, pp. 1294-1304, Jan. 2014.

[20] N. E. Zakzouk, A. K. Abdelsalam, and A. A. Helal, "Modified variable-step incremental conductance maximum power point tracking technique for photovoltaic systems," in Proc. IEEE IECON, pp. 1741-1748, 2013

[21] A. Pandey, N. Dasgupta, and A. K. Mukerjee, "Design issues in implementing MPPT for improved tracking and dynamic performance," in Proc. IEEE IECON, pp. 43874391, 2006.

[22] W. Xiao and W. G. Dunford, "A modified adaptive hill climbing MPPT method for photovoltaic power systems," in Proc. 35th Annu. IEEE Power Electron. Spec. Conf, pp. 1957-1963, 2004.

[23] J. H. Su, S. J. Yu, and W. Zhao, "Silicon solar cell engineering model," Journal of ActaEnergiae Solaris Sinica, No. 22, pp. 409-412, 2001.

[24] Y. Chen, Z. Lai, and R. Liang, "A novel auto-scaling variable step-size MPPT method for a PV system," Solar Energy, Vol. 102, pp. 247-256, Apr. 2014.

[25] R. Kadri, J.-P. Gaubert, and G. Champenois, "An improved maximum power point tracking for photovoltaic grid-connected inverter based on voltage-oriented control," IEEE Trans. Ind. Electron., Vol. 58, No. 1, pp. 66-75, Jan. 2011.

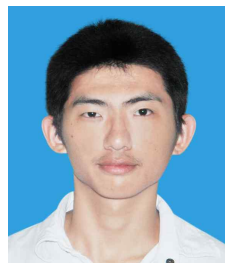

Zhi-rong Xu was born in China, in 1989. He received his B.S. degree in Electrical Engineering from the South China University of Technology, Guangzhou, China, in 2013. In 2013, he began pursuing his Ph.D. degree at the South China University of Technology. His current research interests include clean energy power generation technology and micro-gird energy management.

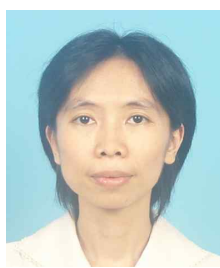

Ping Yang was born in China, in 1967. She received her Ph.D. degree in Control Theory and Engineering from the South China University of Technology, Guangzhou, China, in 1998. She is presently a Professor at the South China University of Technology. She is also the Director of the National-Local Joint Engineering Laboratory for Wind Power Control and Integration Technology. Her current research interests include the integration of renewable energy sources into power systems.

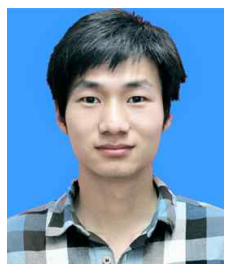

Dong-bao Zhou was born in Henan, China. $\mathrm{He}$ received his B.S. degree at the Tianjin University of Technology, Tianjin, China, in 2013. He is presently working toward his M.S. degree at the South China University of Technology, Guangzhou, China. His current research interests include renewable energy applications.

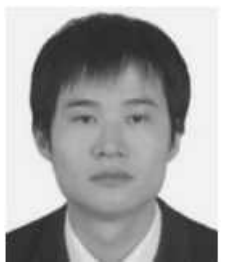

Peng Li received his first Ph.D. degree from the South China University of Technology, Guangzhou, China, in 2002, and his second Ph.D. degree from the Braunschweig University of Technology, Braunschweig, Germany, in 2004, both in Electrical Engineering. He is a Senior Engineer with the China Southern Power Grid Co., Guangzhou, China, where he is responsible for the Automation Division in the CSG Dispatching Center. His expertise includes IT applications, gird analysis, and high voltage technology. Currently, he is mainly involved in the implementation of the CSG EMS project.

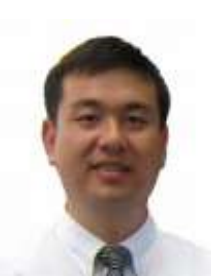

Jin-yong Lei received his B.S. and Ph.D. degrees from Zhejiang University, Zhejiang, China, in 2005 and 2010, respectively, both in Electrical Engineering. Since July 2010, he has been a Research Associate with the Electric Power Research Institute, China Southern Power Grid Co., Guangzhou, China His current research interests include energy, and micro-grids. distributed generation systems, renewable

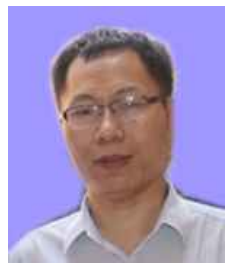

Yuan-rui Chen was born in Jiangxi, China. He received his B.S. degree from the Harbin Engineering University, Harbin, China, in 1991. He received his Ph.D. degree from the South China University of Technology, Guangzhou, China, in 2002. From 2000 to 2001, he was with the Hong Kong Polytechnic University, Hong Kong, China, where he worked on robust control techniques in permanent magnet servomotors. Since 2002, he has been an Assistant Professor at South China University of Technology. His current research interests include power electronic converters, the circuits and control of high efficiency integrated electric energy conversion systems, and the application of renewable energy. 